\title{
Radial Turbine with Pitch-Controlled Guide Vanes for Wave Energy Conversion
}

\author{
M. Takao', Y. Fujioka ${ }^{1}$, H. Ito ${ }^{2}$ and T. Setoguchi ${ }^{2}$ \\ 'Department of Mechanical Engineering, Matsue National College of Technology \\ 14-4 Nishiikuma-cho, Matsue-shi, Shimane 690-8518, Japan \\ ${ }^{2}$ Department of Mechanical Engineering, Saga University \\ 1 Honjo-machi, Saga-shi, Saga 840-8502, Japan
}

\begin{abstract}
In order to develop a high performance radial turbine for wave energy conversion, a radial turbine with pitch-controlled guide vanes has been proposed and investigated experimentally by model testing. As a result, the performances of the presented radial turbine have been clarified under steady flow conditions. Furthermore, it seems that the presented radial turbine is superior to a conventional radial turbine, i.e., a radial turbine with fixed guide vanes.

\section{Introduction}

The performance of radial flow turbines, which can be used for wave energy conversion using the oscillating water column principle, has been studied by a number of authors [1-4, 8]. It was found that the efficiency of radial turbines using reaction-type rotor blading was extremely low $[1,2]$. On the other hand, the efficiency of impulse blading is higher according to the studies [3, 4]. However, detailed performance characteristics of impulse-type radial turbines were not found in the literature. In an attempt to fill this gap, performance characteristics were measured on turbines (508.8 $\mathrm{mm}$ rotor diameter) with different guide vane geometries by the authors [7]. Performance was also measured for flow radially inward and outward through the turbine, which is made possible by an oscillatory flow rig. As a result, it was clarified by the authors [7] that the turbine efficiency of impulse blading was not so high because there are large differences between the absolute outlet flow angle and setting angle of the downstream guide vane, and the downstream guide vane doesn't work as a diffuser.
\end{abstract}

In order to overcome the above drawback and enhance the performance of the radial turbine, the authors have proposed a radial turbine with pitch-controlled guide vanes for wave energy conversion. As the first step to an analysis of the presented radial turbine, the turbine characteristics under steady flow conditions have been clarified in the paper.

\section{Experimental Apparatus and Procedure}

The test rig consists of a large piston-cylinder, one end of which is followed by a settling chamber as shown in figure 1 . The radial turbine's axial entry/exit is attached to the settling chamber as shown in figure 2. The piston can be driven back and forth inside the cylinder by means of three ball screws through three nuts fixed to the piston. All three screws are driven by a d.c. servo-motor through chain and sprockets. A computer controls this motor and hence the piston velocity to produce any airflows (intermittently for short periods). The test turbine rotor shaft is coupled to the shaft of a servo-motor-generator through a torque transducer. The motorgenerator is electronically controlled such that the turbine shaft angular velocity is held constant at any set value. The flow rate through the turbine $Q$, whether it is inhalation (flow from the atmosphere into the rig) or exhalation (flow from the rig to the atmosphere), is measured by Pitot tube survey. The radial flow velocity $v_{\mathrm{R}}$ at mean radius $r_{\mathrm{R}}$ in the turbine is calculated from $Q$ $=A_{\mathrm{R}} v_{\mathrm{R}}$ where $A_{\mathrm{R}}$ is the flow passage area at mean radius $\left(=2 \pi r_{\mathrm{R}} h\right)$. In a typical test, for a particular turbine geometry, the volumetric flow rate $Q$, pressure difference between settling chamber and atmosphere $\Delta p$, turbine torque $T_{\mathrm{o}}$ and turbine angular velocity $\omega$ are all recorded. Thereby, data for one flow coefficient $\phi$ defined in

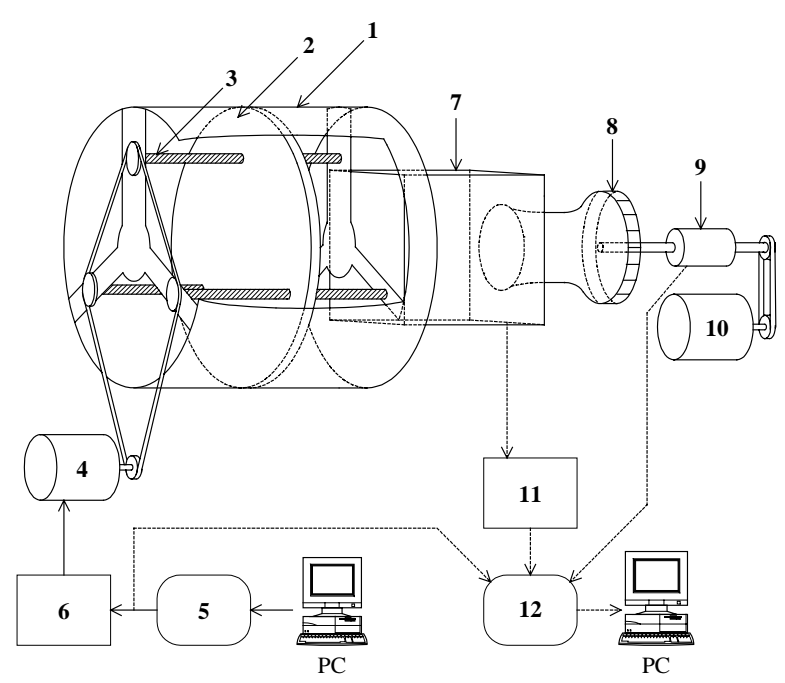

1 Wind tunnel

2 Piston

3 Ball-screw

4 Servomotor

$5 \mathrm{D} / \mathrm{A}$ converter

6 Servo-pack

7 Settling chamber

8 Radial turbine

9 Torque transducer

10 Servomotor-genereator

11 Pressure transducer

$12 \mathrm{~A} / \mathrm{D}$ converter

Figure 1: Test apparatus.

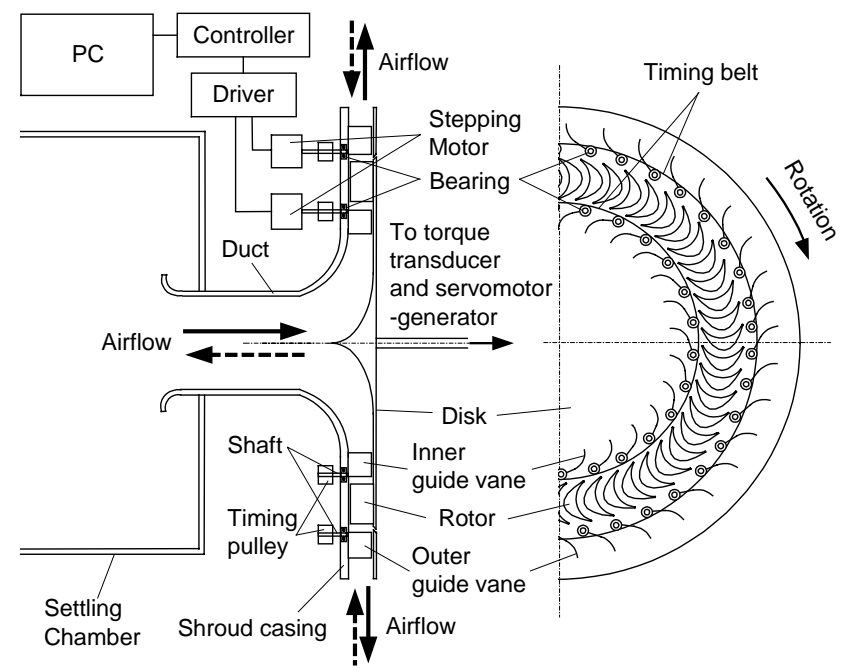

Figure 2: Radial turbine with pitch-controlled guide vanes. 


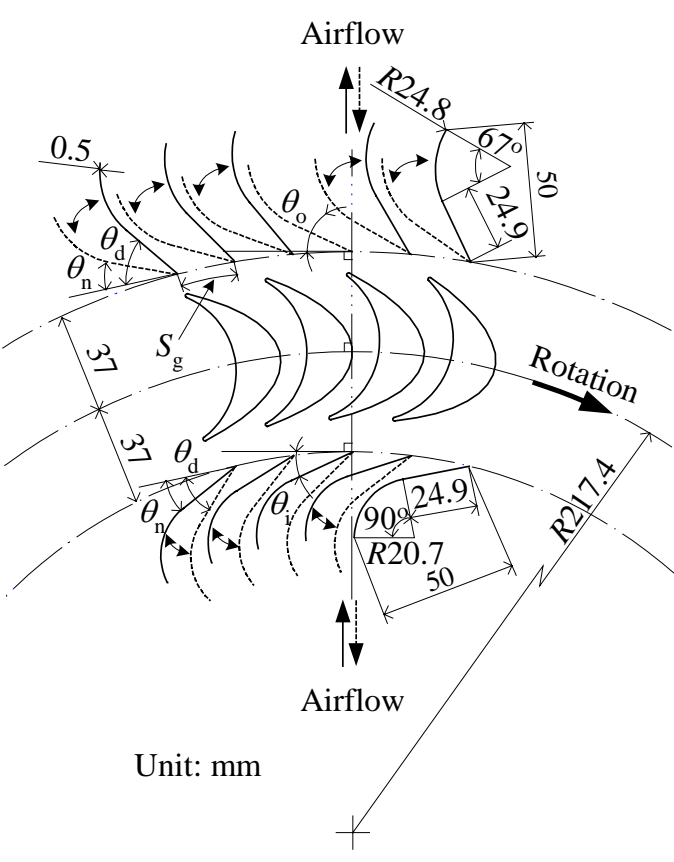

Figure 3: Configuration of turbine.

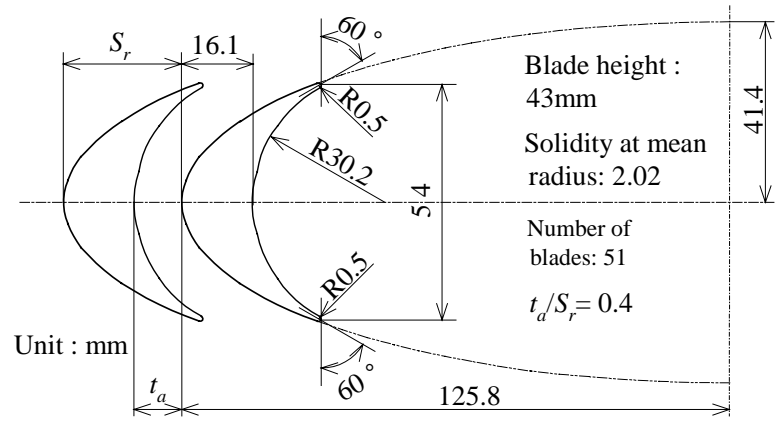

Figure 4: Rotor blade.

equation (4) are obtained. Data for a range of flow coefficients are collected by varying flow rate or turbine angular velocity. Tests were performed with turbine shaft angular velocities $\omega$ up to 68.1 $\mathrm{rad} / \mathrm{s}$ and flow rates $Q$ up to $0.275 \mathrm{~m}^{3} / \mathrm{s}$. The Reynolds number based on the blade chord was approximately $3 \times 10^{4}$ at conditions corresponding to the peak efficiency of the turbine. The measurement uncertainty in efficiency is about $\pm 1 \%$.

The radial turbine shown in figure 2 was tested at a constant rotational speed under steady flow. The sign and magnitude of the torque of the motor-generator is servo controlled so as to hold the turbine speed constant even if the flow velocity is varying with time. The part of shroud casing and the part of disk covering the inner guide vane to the exit are flat and parallel to each other. The height of flow path of the turbine $h$ (gap between the shroud casing and the disk) is $44 \mathrm{~mm}$. The flow passage from inlet to inner guide vane entry has been shaped such that the flow area is constant along this passage. The turbine system has guide vanes before and behind the rotor so as to operate efficiently in a reciprocating airflow. They are set by pivots on the shroud casing wall as shown in figure 2. The pivots are located at the end of the guide vane chord close to the rotor. The guide vanes are controlled by the stepping motors, timing pulleys and timing belts. Each cascade of outer and inner guide vane changes the pitch angle simultaneously when the airflow direction changes. These guide vanes rotate between two angles, i.e., nozzle setting angle $\theta_{\mathrm{n}}$ (upstream side of the rotor) and diffuser setting angle $\theta_{\mathrm{d}}$ (downstream one) as shown in figure 3. However, the pitch angle is set at a particular value because tests are performed under steady flow conditions in the study.

The guide vane geometries are shown in figure 3 . The guide vane consists of a straight line and circular arc. Details of the guide vanes are given by chord length of $50 \mathrm{~mm}$; solidity of inner guide vane at $r_{\mathrm{R}}$ of 1.15; solidity of outer guide vane of 1.16 . The nozzle setting angle $\theta_{\mathrm{n}}$ is only $15^{\circ}$ for both the airflow direction. In order to clarify the effect of the diffuser setting angle $\theta_{\mathrm{d}}$ on the turbine characteristics $\theta_{\mathrm{d}}$ is $20^{\circ}$ to $60^{\circ}$ for the inner guide vane in the case of inhalation, and $30^{\circ}$ to $90^{\circ}$ for the outer guide vane in the case of exhalation. Rotor blade geometry is shown in figure 4 and is the same as what was used in previous studies $[5,6]$. The blade profile consists of a circular arc and on the pressure side and part of an ellipse on the suction side. The ellipse has semi-major axis of $125.8 \mathrm{~mm}$ and semi-minor axis of $41.4 \mathrm{~mm}$. Detailed information about the blade profile is as follows: chord length of $54 \mathrm{~mm}$; tip clearance of $1 \mathrm{~mm}$; mean radius of $r_{\mathrm{R}}=217.4 \mathrm{~mm}$; blade inlet (or outlet) angle of $60^{\circ}$; thickness ratio of 0.3 . The blade is oriented such that the blade profile is tangent to a radial line at the maximum thickness point on the suction side which can be seen clearly for the second blade from the left in figure 3 .

\section{Results and Discussion}

Experimental results on the running characteristics of the turbine are expressed in terms of the torque coefficient $C_{\mathrm{T}}$, input coefficient $C_{\mathrm{A}}$ and efficiency $\eta$, which are all plotted against the flow coefficient $\phi$. The various definitions are

$$
\begin{gathered}
C_{\mathrm{T}}=T_{\mathrm{o}} /\left\{\rho\left(v_{\mathrm{r}}^{2}+U_{\mathrm{R}}^{2}\right) A_{\mathrm{R}} r_{\mathrm{R}} / 2\right\} \\
C_{\mathrm{A}}=\Delta p Q /\left\{\rho\left(v_{\mathrm{r}}^{2}+U_{\mathrm{R}}^{2}\right) A_{\mathrm{R}} v_{\mathrm{R}} / 2\right\}=\Delta p /\left\{\rho\left(v_{\mathrm{r}}^{2}+U_{\mathrm{R}}^{2}\right) / 2\right\}
\end{gathered}
$$

where $\rho$ and $U_{\mathrm{R}}$ are density of air, rotational speed at $r_{\mathrm{R}}$, respectively. Efficiency, which is the ratio of shaft power output to pneumatic power input, can be expressed in terms of the coefficients mentioned above:

$$
\eta=T_{\mathrm{o}} \omega /(\Delta p Q)=C_{\mathrm{T}} /\left(C_{\mathrm{A}} \phi\right) .
$$

The flow coefficient is defined as

$$
\phi=v_{\mathrm{R}} / U_{\mathrm{R}} .
$$

Figures 5 and 6 show the effect of setting angle of the inner guide vane on the turbine characteristics under steady flow conditions. In figure $5 c$ the solid line represents the efficiency of the radial turbine with fixed guide vanes which has the optimum setting angle $\left(\theta_{1}=\theta_{0}=25^{\circ}\right)$ [7]. When the flow direction is from atmosphere to settling chamber (i.e. inhalation) the inner guide vane is downstream of the rotor and it works as a diffuser. Consequently, the torque coefficient $C_{\mathrm{T}}$ is independent of $\theta_{\mathrm{1}}$ (figure $5 \mathrm{a}$ ), whereas the input coefficient $C_{\mathrm{A}}$ decreases with increasing $\theta_{1}$ for $\theta_{1} \leq 40^{\circ}$ (figure 5b). Then, $C_{\mathrm{A}}$ increases with $\theta_{\mathrm{i}}$ for $\theta_{\mathrm{i}} \geq 40^{\circ}$. Combining the above results and equation (3), it is evident that the highest efficiency occurs for the highest value of $\theta_{1}=40^{\circ}$ and its value is approximately 0.45 when the flow is 'from atmosphere' (figures $5 \mathrm{c}$ and 6). Moreover, it can be observed from figure $5 \mathrm{c}$ that the efficiency of the presented radial turbine is higher than that of the conventional radial turbine (i.e. the radial turbine with fixed guide vanes) by 0.15 . Conversely, when the flow direction is from chamber to atmosphere (i.e. exhalation), the outer guide vane is downstream of the rotor and it works as a diffuser. Hence, the torque coefficient $C_{\mathrm{T}}$ is independent of $\theta_{\mathrm{o}}$ (figure $7 \mathrm{a}$ ). Regarding $C_{\mathrm{A}^{-}} \phi$ characteristics, $C_{\mathrm{A}}$ decreases slightly with increasing $\theta_{\mathrm{o}}$ for $\theta_{\mathrm{o}}$ $\leq 60^{\circ}$ and $C_{\mathrm{A}^{-}} \phi$ characteristics in the case of $\theta_{0} \geq 60^{\circ}$ are almost the same (figure $7 \mathrm{~b}$ ). As a result, $\eta$ increases with $\theta_{0} \leq 60^{\circ}$ and remains 


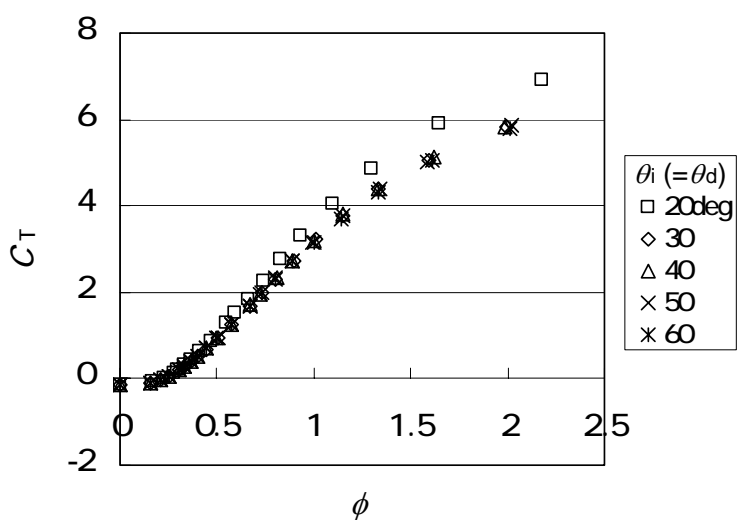

(a) Torque coefficient

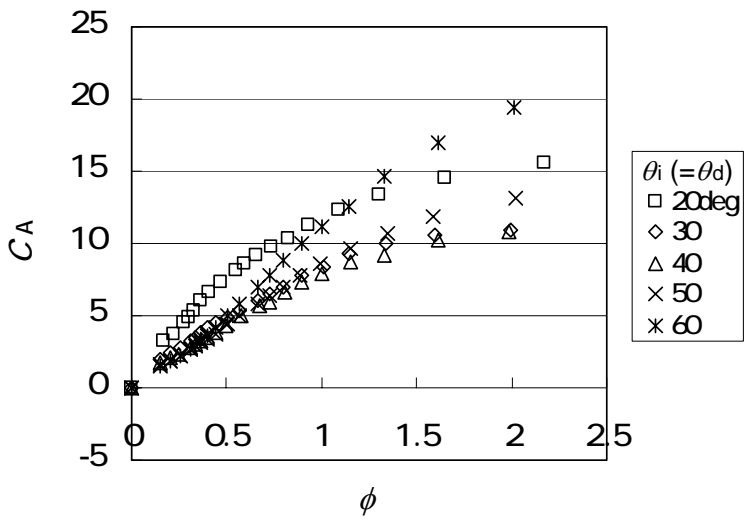

(b) Input coefficient

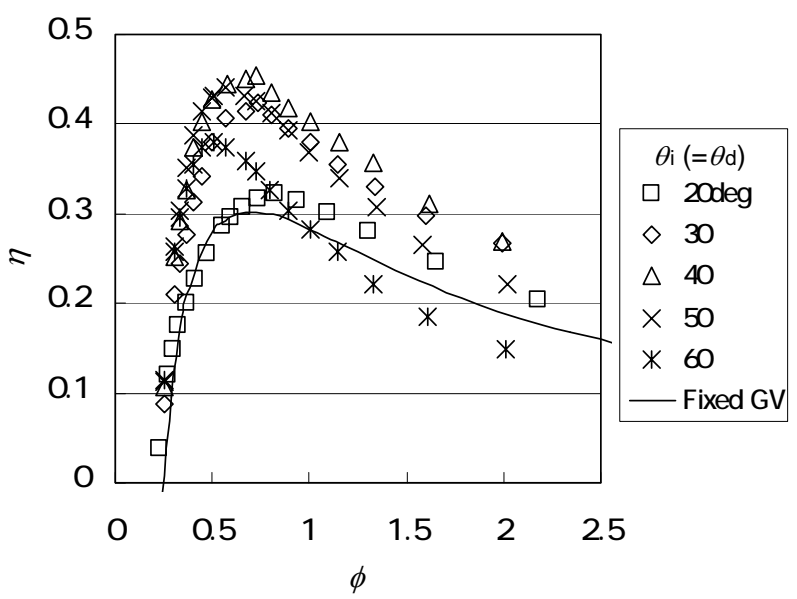

(c) Efficiency

Figure 5: Effect of setting angle of inner guide vane on turbine characteristics (inhalation, $\theta_{\mathrm{o}}=\theta_{\mathrm{n}}=15^{\circ}$ ).

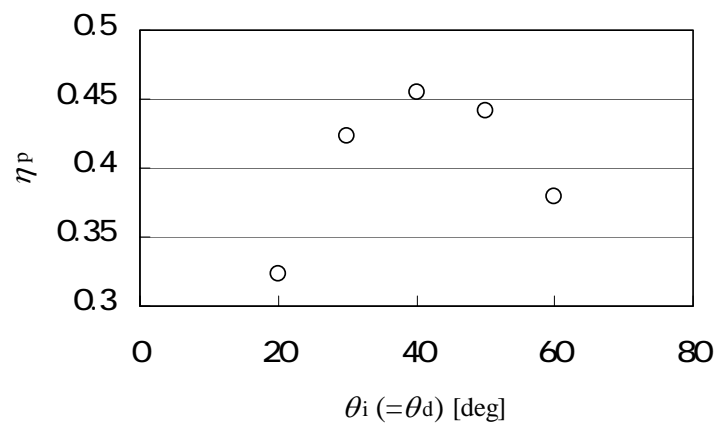

Figure 6: Effect of setting angle of inner guide vane on peak efficiency (inhalation, $\theta_{\mathrm{o}}=\theta_{\mathrm{n}}=15^{\circ}$ ).

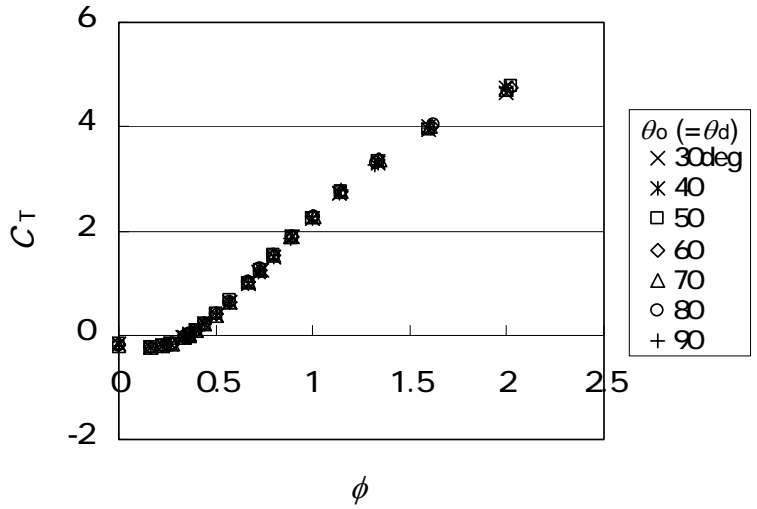

(a) Torque coefficient

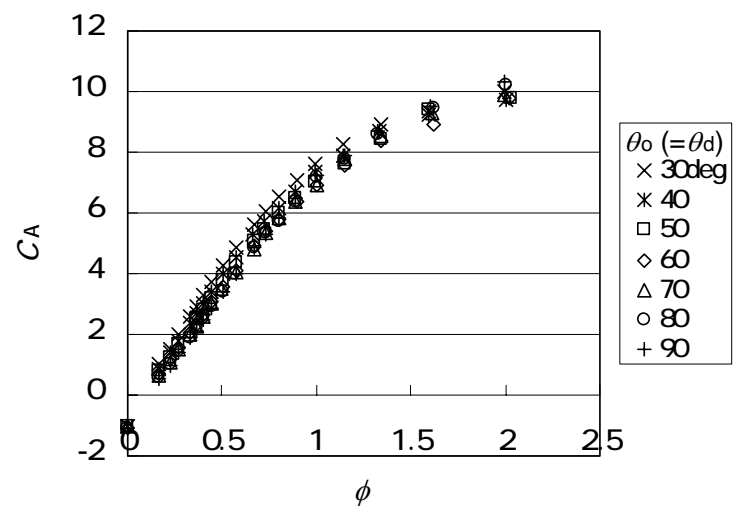

(b) Input coefficient

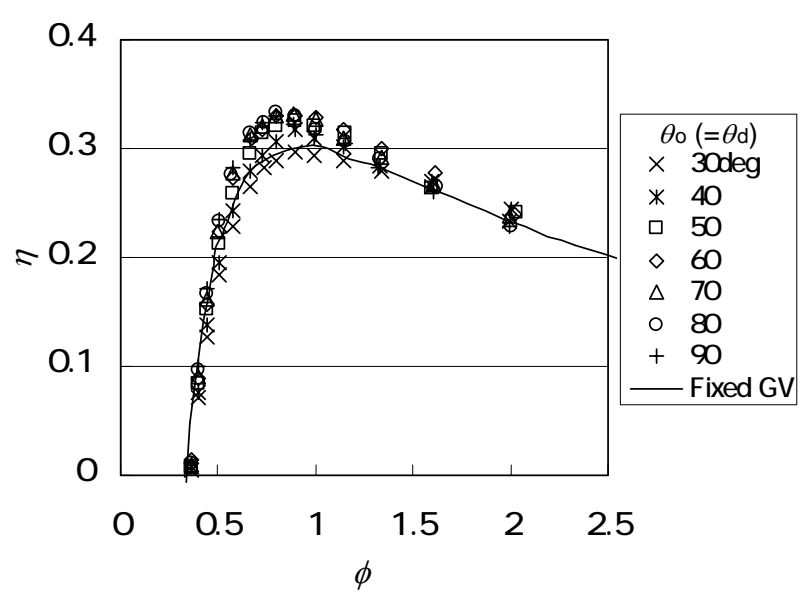

(c) Efficiency

Figure 7: Effect of setting angle of outer guide vane on turbine characteristics (exhalation, $\theta_{\mathrm{i}}=\theta_{\mathrm{n}}=15^{\circ}$ ).

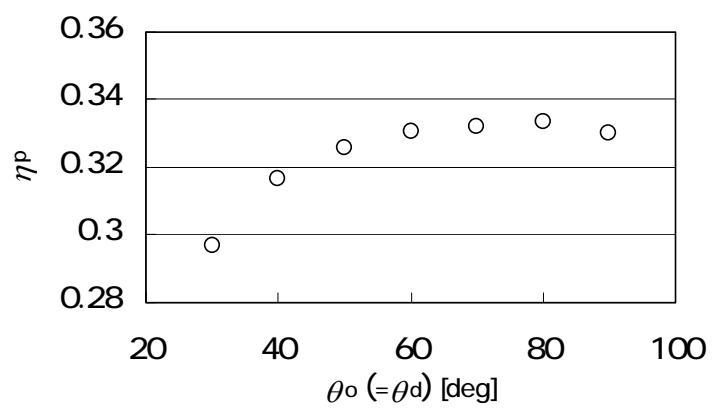

Figure 8: Effect of setting angle of outer guide vane on peak efficiency (exhalation, $\theta_{1}=\theta_{\mathrm{n}}=15^{\circ}$ ). 
a stable situation at round 0.33 (figures $7 \mathrm{c}$ and 8 ). Its efficiency is higher than that of the conventional radial turbine by 0.03 . Looking at the efficiency curves in figures $5 \mathrm{c}$ and $7 \mathrm{c}$, it is seen that higher efficiencies are obtained when the flow is from atmosphere. Therefore, it has been concluded from the above results that the performance of the radial turbine can be improved by using pitchcontrolled guide vanes.

\section{Conclusions}

In order to develop a high performance radial turbine for wave energy conversion, a radial turbine with pitch-controlled guide vanes has been proposed and investigated experimentally by model testing. As the first step to an analysis the presented turbine, the experiment has been carried out under steady flow conditions in the study. Then, the results have been compared with those of a radial turbine with fixed guide vanes by previous studies. As a result, the performances of the presented radial turbine under steady flow conditions have been clarified. Furthermore, it seems that the presented radial turbine is superior to the conventional radial turbine, i.e., the radial turbine with fixed guide vanes.

\section{References}

[1] Kaneko, K., Setoguchi, T. \& Raghunathan, S., Self-rectifying Turbine for Wave Energy Conversion, in 1st International Offshore Polar Engineering Conference, 1, 1991, 385-392.

[2] Kaneko, K., Setoguchi, T. \& Raghunathan, S., Self-rectifying
Turbines for Wave Energy Conversion, Int. J. Offshore Polar Engng., 2(3), 1992, 238-240.

[3] McCormick, M. E., Rehak, J. G. \& Williams, B. D., An Experimental Study of a Bi-directional Radial Turbine for Pneumatic Energy Conversion, in. Mastering Ocean through Technology, 2, 1992, 866-870.

[4] McCormick, M. E. \& Cochran, B., A Performance Study of a Radial Turbine, in 1st European Wave Energy Conference, 1993, 443-448.

[5] Setoguchi, T., Takao, M., Kinoue, Y., Kaneko, K., Santhakumar, S. \& Inoue, M., Study on an Impulse Turbine for Wave Energy Conversion, Int. J. Offshore Polar Engng., 10(2), 2000, 145-152.

[6] Setoguchi, T., Kaneko, K., Taniyama, H., Maeda, H. \& Inoue, M., Impulse Turbine with Self-pitch-controlled Guide Vanes for Wave Power Conversion, Int. J. Offshore Polar Engng., 6(1), 1996, 76-80.

[7] Setoguchi, T., Santhakumar, S., Takao, M., Kim, T.H. \& Kaneko, K., A Performance Study of a Radial Turbine for Wave Energy Conversion, J. Power and Energy, 216(A1), 2002, 15-22.

[8] Veziroglu, T. N. (editor), Alternative Energy Sources VI, Vol. 3, Wind/Ocean/Nuclear/Hydrogen, Hemisphere Publishing Corporation, 1985, 169-181. 